\title{
Thresholds in the Pluralistic Architecture of Tadao Ando
}

\author{
Maryam Farhady ${ }^{1}$ and Jeehyun Nam*2
}

\author{
${ }^{1}$ Ph.D. Candidate, Department of Architecture, The University of Tokyo, Japan \\ ${ }^{2}$ Ph.D. Candidate, Department of Urban Engineering, The University of Tokyo, Japan
}

\begin{abstract}
Ando's pluralistic architecture can be distinguished by its diverse forms, and suggestion of a powerful outward vector. Diversified spaces resulting from such pluralistic character generate distinctive transitional spots referred to as 'thresholds'. Such spots are key features in understanding the attraction and uniqueness of his architecture. This study aims to clarify the typology of the thresholds in Ando's pluralistic works. First, the characteristics of his pluralistic architecture are discussed and then, a number of factors for the analysis of thresholds are clarified. According to these factors, thresholds in selected buildings are analyzed. As a result, four types of threshold are clarified.
\end{abstract}

Keywords: pluralistic architecture; Tadao Ando; threshold; factor; typology

\section{Introduction \\ 1.1 Background}

Tadao Ando's architecture is simple, strong and extremely gentle. It joins simplicity of form to complexity of space, and above all conveys a clear image of life proposed by the simple form. ${ }^{1}$ Ando has continuously introduced common features in his architecture since his early projects. During these decades of development in Ando's spatial composition, his pluralistic works show these features in a clear way. Meanwhile, due to the diversified spaces, particularly in his pluralistic works, distinctive transitional spots referred to as 'thresholds' are generated which give an identity to his spaces. In these thresholds one can see an interaction between forms, or relationships between form and the surrounding context. These spots are key features for understanding the attraction and uniqueness of his architecture.

\subsection{Aim and Methodology}

Rather than taking a holistic approach toward design, this study aims at an anatomical analysis of the thresholds, and aims to clarify the distinctive types of thresholds in Ando's method of spatial composition. According to the characteristics of his pluralistic architecture, a number of factors in the analysis of

*Contact Author: Jeehyun Nam, Ph.D. Candidate,

The University of Tokyo, Japan, Department of Urban Eng., Graduate School of Eng., The University of Tokyo, 7-3-1, Hongo, Bunkyo-ku, Tokyo, 113-8656 Japan Tel: +81-90-6516-1577 Fax: +81-3-5841-6267

E-mail: whlove@gmail.com

(Received April 8, 2010 ; accepted May 27, 2010) the threshold are introduced and described as 'factors in threshold'. Also, the basic 'spatial relationships in building site' between forms or form and context in the location of these thresholds are identified. The most significant thresholds are selected in a number of pluralistic buildings, and are analyzed according to these factors. Then, the typology of thresholds by Ando is clarified. These buildings are located in both built and natural contexts. They show his representative spatial compositions, indicating the wide range of his skills in creating thresholds.

\section{Ando's Pluralistic Architecture \\ 2.1 Development of Three Spatial Mechanisms}

Ando's early creations were concrete boxes. A comparison between his early small scale works and latter large scale ones shows that the corners of the concrete box have been opened, and the form is slowly dismantled until it becomes a composition of freestanding planes. According to Masao Furuyama, the character of Ando's architecture as a mechanism for generating emotional response, could be divided into three categories: architecture of monism, dualism, and pluralism. His monistic architecture is characterized by pure form, lucid outlines, and strong space, which includes the small houses and churches of the early phase of his career. These works are ruled by a unifying rhythm that proceeds from the whole to the parts. In his dualistic architecture, space is ruled by the fluid force generated by two mutually attracting and repelling poles. Form and space engage in a contest that neither can win. ${ }^{2}$

\subsection{Features of Ando's Pluralistic Architecture}

Pluralistic architecture denotes the large-scale 
works which Ando has created since 1985. They are distinguished by the diverse forms they employ and their suggestion of a powerful outward vector. Here, the force long gathering in his architecture has dispersed; forms are lighter in visual weight and scattered in arrangement. His pluralistic architecture shows a turning from inside to outside, or more specifically, a change from centripetal vector space to centrifugal vector space, and from depth to surface layer. ${ }^{2}$ Pluralistic architecture is distinguished by its frequent use of curves and variety of angles. As a result, architectural elements that were suppressed under monism or dualism become rehabilitated, and the architecture moves from space to form, from interior to exterior, and from prison cell to festive space. ${ }^{2}$ Form obtains its release from service as a vessel for meaning (space), becomes a vacant sign (form), and creates a world purely of form. The liberation of form means freeing the form to move and pursue its own amusement. Space accordingly, becomes a secondary product of the formal conflict, burying the gaps between forms. His aim is to liberate architecture from being a tool in the pursuit of the universal. ${ }^{2}$

\section{Threshold in Ando's Pluralistic Architecture 3.1 Definition of Threshold}

In general, the threshold provides the key to the transition and connection between areas with divergent territorial claims. It constitutes, essentially, the spatial condition for the meeting and dialogue between areas of different orders. It is a place where two worlds overlap.

In comparison with his monistic or dualistic works, in Ando's pluralistic architecture extroversion of form, combination of free forms, frequent use of curves and variety of angles, generate the accumulation of thresholds. As a result, the number and diversity of thresholds in pluralistic works, makes their analysis easier than other categories. In his pluralistic works, the diversified connections both inside and outside of a building and the behavior of the surfaces of the form in such spots generate thresholds. In other words, here, the thresholds are transitional points where surfaces interface with each other, or the place where the forms open up to the surrounding context. Therefore, the threshold is not static. On the contrary, it has dynamic movement in its spatial composition.

\subsection{Factors in Threshold}

In Ando's pluralistic architecture, the free association of parts supplants the rule of overall form. We confirm in this his embarking from a methodology of division of the whole to one of accumulation of parts. ${ }^{2}$ These parts generate various joint spots in his architecture. The connection and overlapping of joining and separation is the true focus of Ando's compositions. A procedure of connection and separation that he utilizes in designing the shiftings and rotations can constantly be noted in the plans of his edifices. ${ }^{4}$ In his works, the methods of managing relationships of forms diversify, and forms are not limited to intersecting at right angles. The governing by a static geometry has been usurped by change and movement. ${ }^{5}$ In Ando's pluralistic architecture, though low in terms of density of distribution, the architecture inscribes orbits of diffusion and accumulation, drawing our awareness to the tranquil scenery. ${ }^{2}$ Ando states that architecture is the art of articulating the world through geometry. However the world is not articulated as isotropic, homogeneous spaces. A space is not the absolute space of Newtonian physics, that is, a universal space, but a space with meaningful directionality and a heterogeneous density that is born of a relationship to what he chooses to call 'shintai'. By shintai he means a union of spirit and flesh. Ando states that spatiality is the result, not of a single, absolute direction of vision, but of a multiplicity of directions of vision from a multiplicity of viewpoints made possible by the movement of shintai, and natural movement such as light, wind, or rain can change the phenomenal (as opposed to physical) distance between the self and the object. By introducing nature and human movement into simple geometrical forms, he has been trying to create complex spaces. ${ }^{6}$ In Ando's work there is an architectural promenade, guided by ramps, stairs, levels, vistas, glimpses of water, changing qualities of light and the dynamic interaction of bounding surfaces. ${ }^{1}$ In his architecture, larger apertures and openings at corners are directly responsible for the shift to greater illumination, and are closely linked to changes in the forms. ${ }^{5}$ By positioning a number of walls at certain intervals, he creates openings. Walls are freed from the simple role of closure. ${ }^{6}$ Ando's discovery of landscape thus becomes a rich and complex story of the marriage of geometry and nature. Nature destroys geometry, but also sets geometry to work. Nature supplies the energy needed to operate geometry, while giving it fluidity and eroding static order. ${ }^{5}$ Ando's smooth concrete walls sometimes dissolve in shadow, and sometimes emerge as translucent planes. Ando employs every last corner of a site. His ability to weave exterior and interior space transforms roads, courtyards, sky, and streetlights as if they were intimate interior space. ${ }^{1}$ The amorphous and immaterial elements of sunlight, sky, and landscape are cut out and appropriated by walls. These elements are assimilated as aspects of the architectural space. This tense relationship between inside and outside is based on the act of cutting. Walls cut into sky, sunlight, wind, and landscape at every instant. ${ }^{6}$

According to the above characteristics of Ando's pluralistic architecture, we could categorize the following factors in analysis of the thresholds:

-Joint: indicates the physical point at which two forms interact with each other, and forms have a 
variety of angles.

-Density: indicates heterogeneous distribution of spatial density by diffusion or accumulation of parts.

-Directionality: includes geographic orientation, vistas, and viewpoints to different directions, circulation routes and elements.

-Opening: indicates large openings resulting from the subtraction of a form, or vertical openness of a volume, or is generated by intervals between surfaces.

-Nature: indicates interaction of form and immaterial elements such as water, greenery, and sky.

\section{Interpretation of Thresholds in Ando's Selected Pluralistic Architecture}

Many of the museums designed by Ando could be classified as his most remarkable pluralistic architecture. Among them, four museums are selected, from the 1980s to his recent works, which show his representative methods of physical composition.

\subsection{Introduction to the Selected Examples}

Example 1- Himeji Museum of Literature and Annex (1988-91, 1993-96): The museum is located at the foot of a hill facing Himeji Castle. Ando states that natural features were taken into account in the design so that, mediated by water and greenery, the museum might enter into a dialogue with Himeji Castle and existing buildings on the site. The main building consists of two cubes of the same size overlapping at a 30 degree angle and a cylinder wrapped around one of the cubes. The annex is composed of a glass rectangular box arranged on the axis of one of the cubes of the rectangular box. ${ }^{7}$ (Fig.1.)

Example 2- Naoshima Contemporary Art Museum and Annex, Naoshima (1988-92, 1993-95): It is located on a small island situated in the Inland Sea, one of Japan's most scenic areas. The building is buried underground to assure unobstructed views of the sea and preserve the surrounding scenery. The spacious site creates an impression of lightness and outward orientation. Here, climate and geometry melt into one another. In the museum building, a hotel, an art museum, a restaurant, and a hall are arranged around an enormous cylindrical space. The radial composition of space projects an image of centrifugal force, while the cylinder is a node integrating vertical lines of circulation. Because of the sloping topography, we are underground in one room but find ourselves above ground in the next. The landscape breaks through the perimeter of the building and invades the interior; the rooms are filled, each with a different landscape. A hotel annex was built on a hill behind the museum. Here, we see a water garden at the bottom of an elliptical opening in the hill, while the guest rooms are arranged around the elliptical garden. ${ }^{8}$ (Fig.2.)

Example 3- Garden of Fine Arts, Kyoto (199094): This is an outdoor museum for the enjoyment of masterpieces of art while in contact with natural phenomena such as light, wind, and water. An enclosed area is created below ground level within which three walls and circulation consisting of bridges and ramps create a rich variety of spaces on three levels. Water is introduced into the experience through three waterfalls and pools at each level. According to Ando, here he seeks to create the experience of a contemporary volumetric version of a stroll garden. ${ }^{9}$ Gardens are usually designed horizontally, but in this garden museum walkways are integrated vertically. ${ }^{10}$ (Fig.3.)

Example 4- 21_21 Design Sight, Tokyo (200407): Located in the compound of Tokyo Midtown, the building is a low-rise structure consisting of one ground floor and one underground floor. Seventy percent of the volume of the structure is built underground where two galleries and a naturally lit sunken court create a dynamic atmosphere. The ground floor houses the entrance and reception area. Ando devised the idea for the roof as one sheet of folded steel using "a piece of cloth" as the central concept. ${ }^{11}$ (Fig.4.)

\subsection{Analysis of Examples by Factors of Threshold}

Ando's way of creating a challenge between diverse forms, and between form and its context, in both interior and exterior territories is his basic playground in the formation of thresholds. In the analysis of his works, these issues are identified as 'spatial relationship in building site'. As shown in Table 1., thresholds in the above examples are analyzed according to the relation of 'factors in threshold' and 'spatial relationship in building site'. As a result, the following features are clarified in the thresholds of the examples:

Joint: In the Himeji Museum, the two cubic forms are overlapped, as if one cuts into the other. In the Naoshima Museum, a corner of the rectangular shape volume enters the cylinder and forms a small room. This room could be taken as the joint of these large volumes. In the middle part of the site of the Garden of Fine Arts, a number of surfaces are integrated with sharp angles as if woven together. Also, there are vertical layers of walkways in another spot. In 21_21, one can see the integrated surfaces both in the entrance part and the corner of the building.

Density: In the Himeji Museum, one of the overlapped cubes is a closed volume but the other one is a void made of frames, which has generated the heterogeneous density of the threshold. In the Naoshima Museum, the small room in the integrated part of the cylinder and another volume generates an accumulated corner, increasing density. In the Garden of Fine Arts, a number of integrated surfaces are accumulated in the threshold spot, and have increased density, while in 21 21, the visual effect is as if the heavy part of the roof has been folded to the ground. This accumulation of form gives a feeling of difference in weight and density.

Directionality: In the Himeji Museum, the folded 

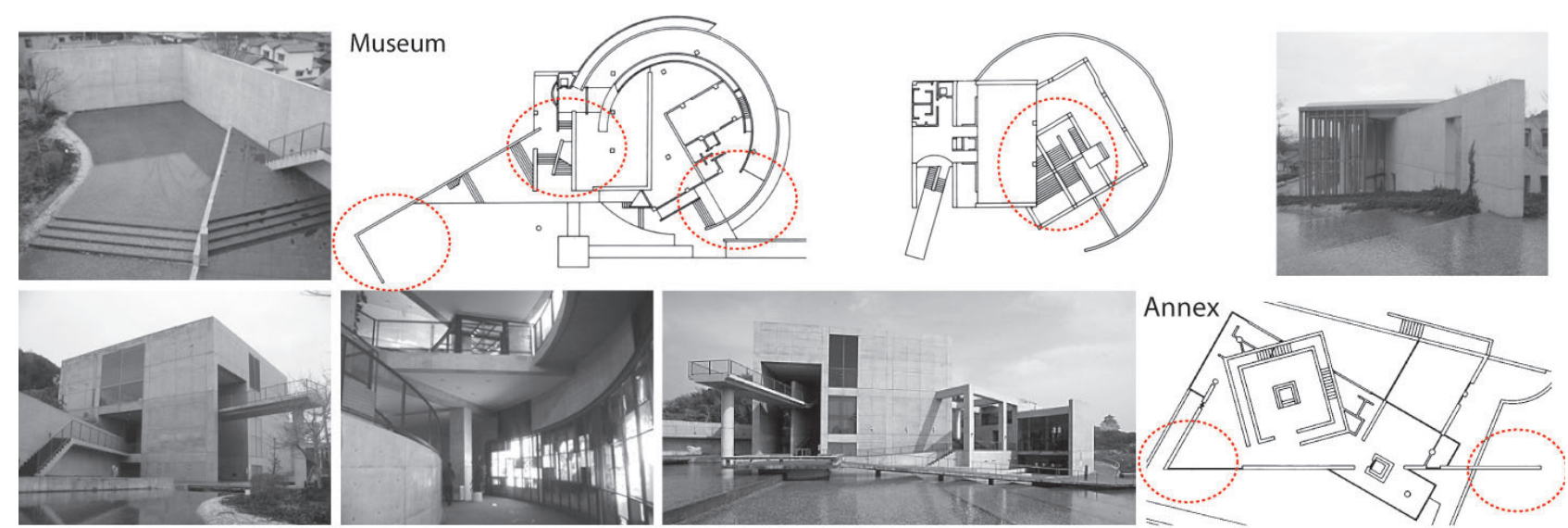

Fig.1. Himeji Museum of Literature and Annex (1988-91, 1993-96)
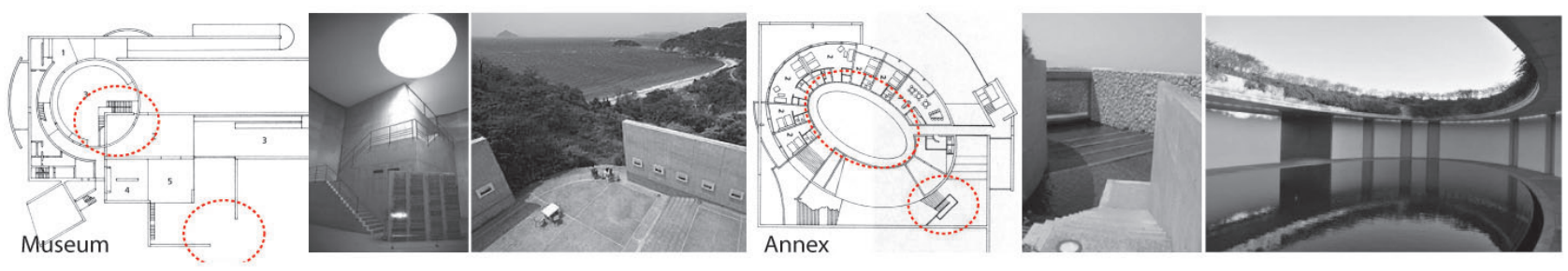

Fig.2. Naoshima Contemporary Art Museum and Annex, Naoshima (1988-92, 1993-95)
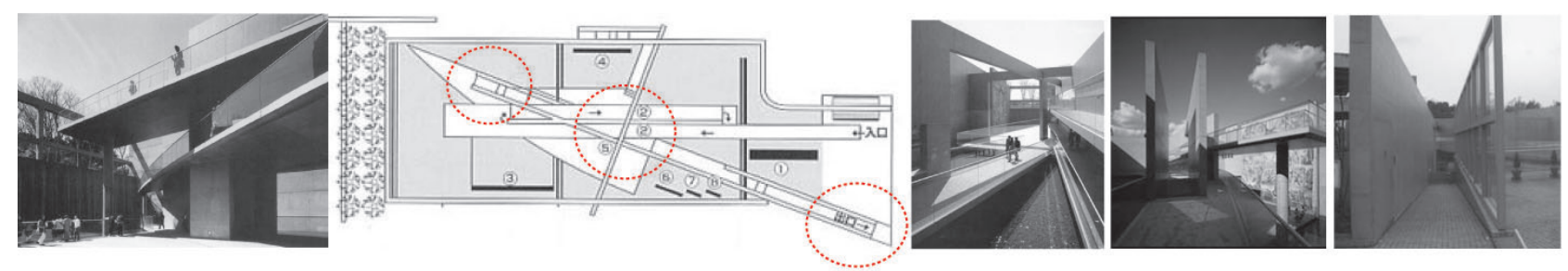

Fig.3. Garden of Fine Arts, Kyoto (1990-94)
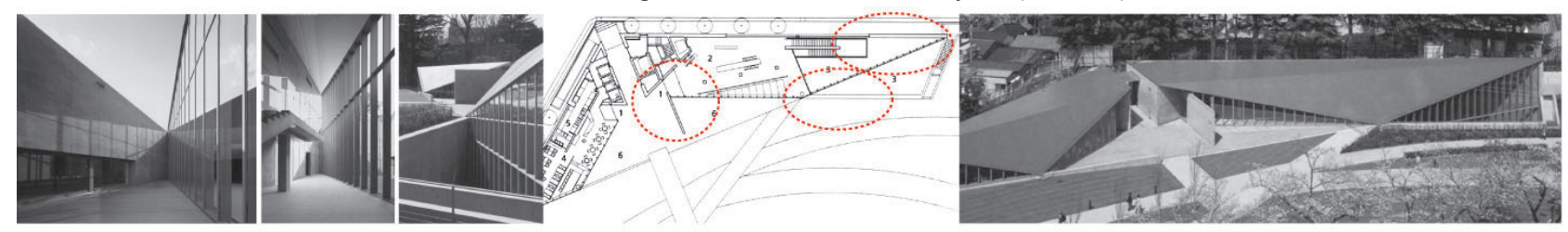

Fig.4. 21_21 Design Sight, Tokyo (2004-07)

curved surface intersects with one of the cubes in the entrance, and the curved wall defines the circulation route from the entrance toward the middle of the building. In another threshold, a folded curved surface intersects with the other cube. Here, staircases are placed in various directions to secure circulation, while a deck that passes through the cube to the outside, produces an outward viewpoint. In the Naoshima Museum, two curved surfaces exist in parallel from the entrance area, leading the visitor to pass through the gap between them. In the Garden of Fine Arts, a spatial sequence including bridges and ramps passes through the entire building. In the exit area, two long surfaces stand in parallel as two layers, controlling the viewpoint. At the opposite side of the site, other parallel surfaces have a staircase in between, and lead the viewpoint to the sharp edge of the bridge. In 21_21, the non-linear character of the folded roof helps it to touch the ground, and makes a smooth orientation toward its context. In the threshold of the interior part of the building two surfaces integrate with a sharp angle toward the outside. Here, one can see a staircase along the surface.

Opening: In the Himeji Museum, the volume of one of the cubes is cut by the stairs and a deck, making large openings to the outside, while in the annex of the Naoshima Museum, an elliptical form has an upward opening. In the Garden of Fine Arts, the subtraction of surfaces generates large openings in an integrated spot through which the walkways pass. Also, in two spots one can see parallel surfaces which make intervals in between. In 21_21, the threshold in the interior part has a large glass wall open to the sunken court.

Nature: In the Himeji Museum, a surface in the exterior part frames water, while in its annex, the extension of its surface notionally breaks through 
Table 1. Analysis of the Thresholds in Tadao Ando's Pluralistic Architecture

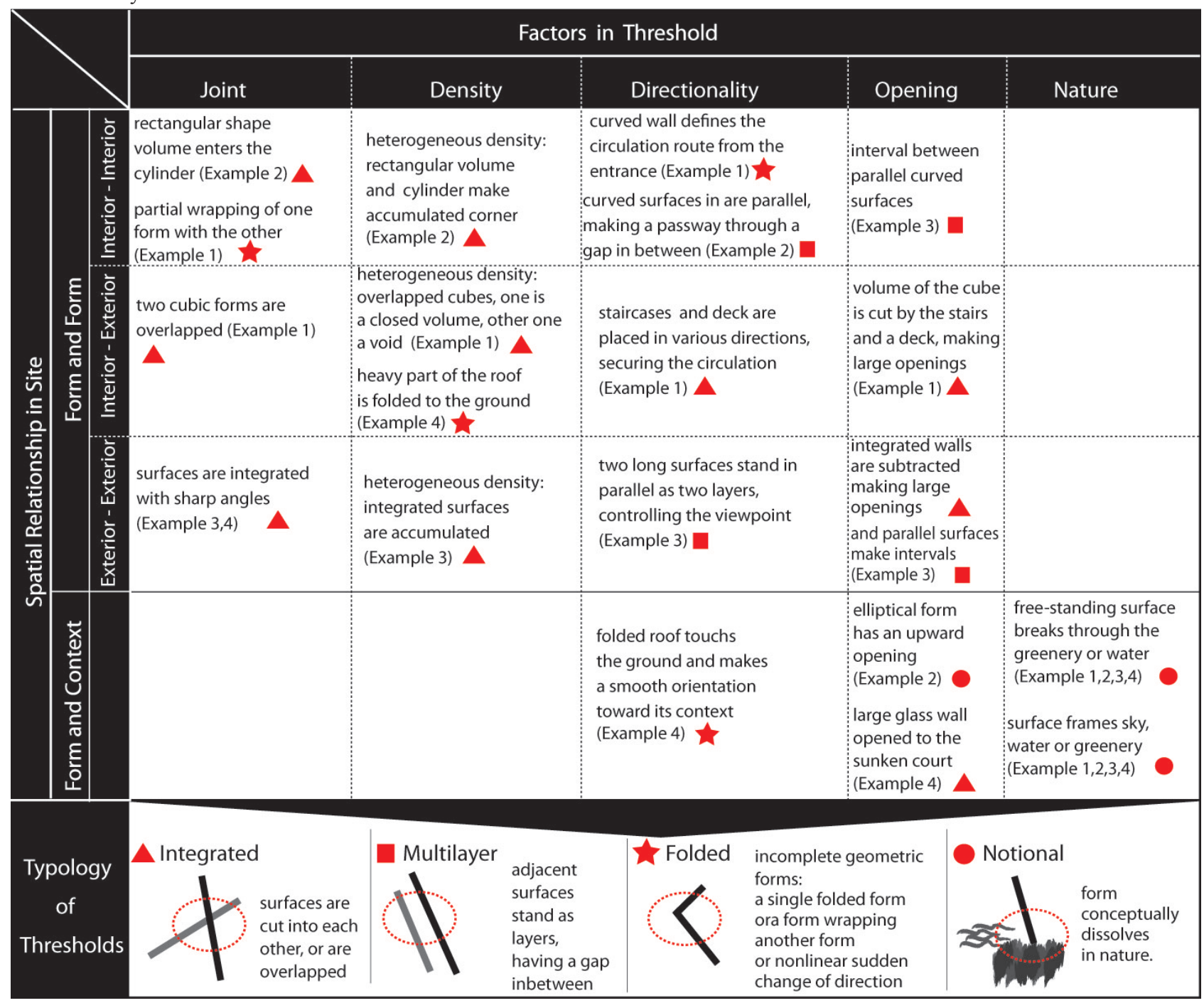

the water. In the Naoshima Museum, the building appears to melt into the landscape so that the freestanding surfaces in one of the courts break through the greenery facing the sea. In the annex, another surface cuts into the water, while in the elliptical opening of the annex in the Naoshima Museum, and the sunken court of 2121 , surfaces seem to have framed the sky. In the Garden of Fine Arts, surfaces cut into the water pools which surround the building.

\subsection{Typology of Thresholds in Ando's Pluralistic Architecture}

As shown in Table 1., according to the above analysis of the thresholds in the selected examples, it is possible to distinguish some common keywords which indicate a kind of threshold; including integration, folding, multi-layering and notional transition area in relation with nature. These are classified as types of thresholds in Ando's pluralistic architecture:

\section{- Integrated Threshold:}

Here, surfaces are cut into each other, overlapped or interwoven, creating complex mixtures through joint manipulations. In the Garden of Fine Arts, a number of surfaces are integrated with sharp angles, resulting in a multiplicity of viewpoints, while in the Himeji and Naoshima Museums, large volumes with both curved and straight lines are integrated.

\section{- Multilayer Threshold:}

Here, adjacent surfaces stand as layers, having a gap in between. In the Garden of Fine Arts and the Naoshima Museum, one can see parallel straight lines and parallel curved lines, which show strong directionality. Passages or stairways exist along their gaps, which support circulation.

\section{- Folded Threshold:}

Here, the surfaces are folded by various angles either connected to other forms in interiors, or stand freely in the exterior part of the site, and are usually incomplete geometric forms. More than other types, the folded threshold shows an inward-oriented accumulation of form, resulting in a heterogeneous density of form. Folded surfaces in the exteriors enfold natural elements such as water and greenery, as seen in the Himeji Museum, and make a quick transition to a wall with sharp angle in its annex building. Another kind of 
folding appears when a form wraps another form. In the Himeji Museum, a curved surface wraps a straightline surface, while in the Naoshima Museum annex, a straight surface wraps a curved one. Also, in 21_21, one can see another method of folding, represented by a nonlinear sudden change of direction in the roof. This threshold is the result of the folding roof and its connection to the exterior space.

\section{- Notional Threshold:}

Here, the architectural form conceptually dissolves and vanishes in nature. This type of threshold shows a kind of ambiguity between architectural and natural elements. It is widely seen when a single free-standing surface cuts into water or greenery. Rather than having strong physical joints, one can see ambiguous boundaries, which define the directions and vistas. This type of threshold exists in the Himeji Museum and its annex, as well as in the Naoshima Museum and its annex. Also, another kind of notional threshold can be seen in the sunken part of a building where the sky is framed by the form. The annex of the Naoshima Museum and 21_21 are examples.

\section{Conclusion}

Ando's pluralistic architecture is in fact the result of a combination of a number of thresholds. Here, in the selected buildings the most significant thresholds were analyzed. According to the characteristics of his pluralistic architecture, five factors in thresholds were clarified; including joint, density, directionality, openings and nature. Selected examples were discussed according to these factors and as a result, four typologies of thresholds in his pluralistic architecture were clarified; including integrated, multilayer, folded and notional thresholds. As shown, the combination of these thresholds is a significant feature in the formation of Ando's architectural composition.

\section{References}

1) Furuyama, Masao. (2006) Tadao Ando: 1941. Taschen. pp.13-15.

2) Furuyama, Masao. (1996) Tadao Ando. Birkhaeuser Basel. pp.1125.

3) Hertzberger, Herman. (2001) Lessons for students in Architecture. 010 Uitgeverij. p.32, 35 .

4) Dal Co, Francesco and Futagawa, Y. (1997) Tadao Ando Details 2. p.8, 9 .

5) Furuyama, Masao. (1996) Tadao Ando. Birkhaeuser Basel. p.30-33

6) Dal Co, Francesco. (1997) Tadao Ando Complete Works. Phaidon. p. $453,449$.

7) Ando, Tadao. (2007) Tadao Ando Details 4. ADA.

8) Furuyama, Masao. (2006) Tadao Ando: 1941. Taschen. p.41-43.

9) (2000) El Croquis, No.44+58 Tadao Ando issues.

10) Ando, Tadao. (2001) Tadao Ando Museum Guide, Bijutsu Shuppan-sha. p.75.

11) Official Homepage of 21_21 Design Sight. 